\title{
PERANCANGAN GAME BERBASIS ANDROID UNTUK MEMPERKENALKAN ADAT MELAYU RIAU
}

\author{
${ }^{1)}$ Atan, ${ }^{2)}$ Zul Indra, ${ }^{3)}$ Anip Febtriko \\ 1,2,3) Teknik Informatika, Fakultas Teknik, Universitas Abdurrab \\ 1,2,3) Jl. Riau Ujung No. 73 Pekanbaru \\ E-Mail :atanmuhammad11@gmail.com,zul.indra@univrab.ac.id,anip.febtriko@univrab.ac.id
}

\begin{abstract}
ABSTRAK
Sulitnya mendapatkan pengetahuan tentang adat lokal khususnya adat melayu Riau ini membuat beberapa orang disekitar belum banyak mengetahui dan masih menerapkan pembelajaran dengan menggunakan buku yang masih kurang terdata dan terlalu monoton. Karena adat melayu terdapat pembahasan yang memerlukan penjelasan mengenai teknik yang digunakan dalam pembelajaran dan pengenalan adat melayu Riau. Riau memiliki banyak kebudayaan, tradisi, dan adat istiadat yang tidak banyak diketahui oleh generasi muda atau masyarakat pada umumnya. Adat dan tradisi yang dipercaya turun temurun dan merupakan identitas suatu daerah harus dijaga dan dilestarikan oleh para generasi muda. Salah satunya adalah adat melayu Riau. Adat dan tradisi tersebut perlu dipublikasikan kepada khalayak masyarakat melalui multimedia salah satunya berbasis Android. Masalah yang didapat kurangnya pengetahuan tentang adat melayu Riau dikalangan masyarakat.dengan adanya aplikasi berbasis android ini nantinya diharapkan dapat melestarikan adat melayu Riau lebih dicintai lagi oleh masyarakat.Ruanglingkup penelitian ini sebatas Makanan khas, pakaian adat, pariwisata Tipe penelitian ini adalah penelitian deskriptive, dengan menggunakan metode survey lapangan dan wawancara dengan sumber langsung. Penelitian ini bertujuan untuk melestarikan adat melayu Riau supaya tidak punah dan bisa dinikmati oleh generasi-generasi berikutnya.
\end{abstract}

Kata Kunci: adat melayu riau, multimedia, android

\begin{abstract}
The difficulty of getting knowledge about local customs especially Riau Malay tradition makes some people around not know much and still apply learning by using books that are still less recorded and too monotonous. Because Malay tradition there is a discussion that requires an explanation of the techniques used in learning and introducing Riau Malay tradition. Riau has many cultures, traditions and customs that are not well known to the younger generation or society in general. Customs and traditions that are believed to be hereditary and are the identity of an area must be maintained and preserved by the younger generation. One of them is Riau's Malay tradition. These customs and traditions need to be published to the public through multimedia, one of which is based on Android. The problem is the lack of knowledge about Riau Malay custom among the community. With this Android-based application, it is hoped that it will be able to preserve Riau Malay tradition more loved by the community. The scope of this study is limited to typical food, traditional clothing, tourism This type of research is descriptive research, using the method of field surveys and interviews with direct sources. This research aims to preserve the tradition of Malay Malay so that it does not become extinct and can be enjoyed by subsequent generations.
\end{abstract}

Keywords: riau's malay tradition, multimedia, android 


\section{PENDAHULUAN}

Indonesia merupakan negara yang memiliki keanekaragaman suku, adat dan budaya. Riau salah satunya memiliki banyak suku adat dan budaya. Bahkan pada sekolah dasar sudah diperkenalkan dengan adat dan budaya Indonesia. Akan tetapi untuk adat lokal kurang banyak disajikan di buku sekolah karna hanya sekilas saja. Hal tersebut terdapat pada kompetensi dasar tiap kurikulum yang selama ini digunakan oleh sistem pendidikan di Indonesia. Kurikulum tersebut mengenalkan keanekaragaman budaya [3]. Salah satu penyebabnya kurangnya minat orang-orang dalam mempelajari budaya dan adat lokal karena saat ini adat lokal hanya dikenalkan lewat buku bacaan sehingga kurang menarik minat untuk mempelajarinya.

Sedangkan membaca buku sekarang ini terlalu monoton atau membuat orang cepat bosan. Dengan adanya multimedia diharapkan user tidak cepat bosan untuk mendapatkan informasi yang dibutuhkan. Diberbagai negara maju dan berkembang berlomba-lomba memberikan sebuah terobosan game, game dimanfaatkan sebagai media pembelajrang [5].

Namun tidak semua orang memiliki minat baca yang tinggi. Oleh karena itu perlu adanya alternatif lain yang lebih efektif untuk mengenalkan keanekaragaman adat pada masyarakat dengan melalui media interaktif. Salah satu media interaktif yang menarik adalah menggunakan sistem pembelajaran melalui game.

Sulitnya mendapatkan pengetahuan tentang adat lokal khususnya adat melayu Riau ini membuat beberapa orang disekitar belum banyak mengetahui dan masih menerapkan pembelajaran dengan menggunakan buku yang masih kurang terdata dan terlalu monoton. Karena adat melayu terdapat pembahasan yang memerlukan penjelasan mengenai teknik yang digunakan dalam pembelajaran dan pengenalan adat melayu Riau.

Dengan seiringnya perkembangan teknologi yang semakin pesat, salah satu metode pengenalan saat ini adalah dengan menggunakan multimedia sehingga masyarakat dapat belajar tentang pengenalan adat melayu Riau lebih mudah dipahami[1].

\section{Pengertian Game}

Game merupakan kata dalam bahasa inggris yang berarti permainan. Permainan adalah sesuatu yang dapat dimainkan dengan aturan tertentu sehingga ada yang menang dan ada yang kalah, biasanya dalam konteks tidak serius atau dengan tujuan refreshing [1]. Suatu cara belajar yang digunakan dalam menganalisa interaksi antara sejumlah pemain maupun perorangan yang menunjukkan strategis yang rasional.

Pada 1947 Thomas Toliver Goldsmith $\mathrm{Jr}$ dan Estle Ray Mann menciptakan permainan simulator rudal Cathode Ray Tube Device Amusement. Permainan ini terinspirasi dari kecanggihan radar Perang Dunia II. Inilah game elektronik pertama yang tercatat dalam sejarah.Meski memiliki unsur permainan, game ini tak popular. Penggunaannya terbatas untuk kepentingan simulasi latihan militer. Tampilannya juga masih sederhana belum berwarna [13].

\section{Aplikasi}

Aplikasi adalah proses dimana keperluan pengguna dirubah dalam bentuk paket perangkat lunak dan atau dalam spesifikasi pada komputer yang yang berdasarkan pada sistem informasi. 
Aplikasi adalah penggunaan dalam suatu komputer, instruksi (intruction) atau pernyataan (statement) yang disusun sedemikian rupa sehingga komputer dapat memproses input menjadi output.

\section{Android}

Android adalah sistem operasi untuk telepon seluler berbasis linux sebagai kernelnya. Saat ini android adalah rajanya smartphone, karena android menyediakan platform terbuka (open source) bagi para pengembang untuk menciptakan aplikasi mereka sendiri. Android Inc. Didirikan oleh Andy Rubin, Rich Milner, Nick Sears, dan Crish White pada tahun 2003. Pada tahun 2005 Android Inc. dibeli oleh google dan dibentukalah Open Headset Alliencekonsorium dari 34 perusahaan hardware, software dan telekominikasi [11].

Android memiliki dua distributor, yaitu google mail service (GMS) dan Open Headset Distributor (OHD). GMS adalah distributor android yang mendapatkan dukungan penuh dari google, sedangkan OHD adalah disrtributor android tanpa dukungan dari google [2].

Saat ini banyak bermunculan vendorvendor untuk smartphone berbasis android, yaitu diantaranya: HTC, Motorla, Samsung, LG, HKC, Huawei, Archos,Sony, Acer dan lainnya. Android menjadi pesaing utama dari smartphone lainnya seperti Apple.

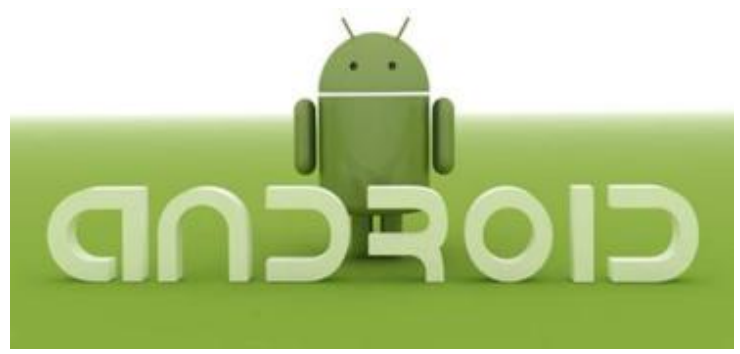

Gambar 1. Android

\section{Smartphone}

Smartphone adalah sebuah teknologi seluler yang dilengkapi dengan berbagai aplikasi di dalamnya, yang dapat dibaratkan sebagai personal computer. Salah satu fitur yang terdapat dalam smar phone adalah layanan internet dan dilengkapi dengan fitur Global Positioning System (GPS) [12]. Dengan adanya GPS pengguna smartphone dapat mengetahui koordinat dari pengguna, yaitu berupa data latitude dan longitude. Selain menggunakan GPS untuk menentukan koordinat pengguna dapat juga menggunakan IP address dari jaringan koneksi internet yang digunakan smartphone [4].

Smartphone atau ponsel pintar atau hp cerdas dilengkapi dengan teknologi tercanggih terbaru dan mutakhir seperti spesifikasi hardware dan software terbaik yang memungkinkan penggunanya dapat melakukan beberapa aktifitas diluar kebiasaan saat menggunakan ponsel atau hp seperti aktifitas internet, browsing, downloading, streaming, uploading dan yang paling digemari adalah aktifitas chating, dan sosial media.

\section{Flowchart}

Flowchart adalah penyajian yang sistematis tentang proses dan logika dari kegiatan penanganan informasi atau penggambaran secara grafik dari langkah-langkah dan urutan-urutan prosedur dari suatu program [14]. Flowchart atau diagram alir adalah sebuah jenis diagram yang mewakili algoritme, alir kerja atau proses, yang menampilkan langkah-langkah dalam bentuk simbolsimbol grafis, dan urutannya dihubungkan dengan panah. Diagram ini mewakili ilustrasi atau penggambaran penyelesaian masalah. Diagram alir digunakan untuk 
menganalisa, mendesain, mendokumentasi atau memanajemen sebuah proses atau program di berbagai bidang.

\section{Adat}

Adat dapat dikatakan sebagai suatu kebiasaan yang mewujud menjadi norma, kaedah, ketentuan, peraturan, nilai, disertai upacara-upacara yang mengikutinya, tidak tertulis dan berlaku serta menjadi pedoman secara turun temurun dari generasi ke generasi oleh masyarakat pendukungnya. Adat istiadat memiliki fungsi sebagai serangkaian aturan yang berlaku di suatu tempat dan telah bersifat turun temurun. Dengan adanya adat istiadat ini suatu tempat menjadi memiliki pedoman untuk menyelesaikan masalah ataupun hendak melakukan kegiatan yang pasti tidak melanggar adat istiadat yang telah di berlakukan.

Tradisi ialah kebiasaan yang turun temurun yang dimulai dari paling sederhana sampai mewujud menjadi adat yang dapat dibedakan menjadi adat sebenar adat, adat yang teradat, dan adat yang diadatkan.

Adat diwariskan dari generasi kegenerasi. Adat termasuk adat istiadat, bahasa, pakaian, bangunan, dan karya seni dan bahasa, sebagaimana juga adat, merupakan bagian yang tidak terpisahkan diri manusia sehingga banyak orang cenderung menganggapnya diwariskan secara genetis [10].

\section{a. Adat Melayu Riau}

Riau sebagai salah satu propinsi di Indonesia yang kaya akan adat melayu. Terdapat banyak sekali jenis adat melayu yaitu: kesenian, upacara adat, busana, bangunan, hukum adatnyadan sebagainya.

Agar adat itu tetap ada, maka wajib untuk menjaga dan melestarikannya [8].
Adat Melayu di Riau dapat dibagi dalam tiga tingkatan, yaitu adat sebenar adat, adat yang diadatkan, dan adat yang teradat.

b. Adat Sebenar Adat

Yang dimaksud dengan "adat sebenar adat" adalah prinsip adat melayu yang tidak dapat diubah-ubah.

c. Adat yang Diadatkan

Adat yang diadatkan adalah adat yang dibuat oleh penguasa pada suatu kurun waktu dan adat itu terus berlaku selama tidak diubah oleh penguasa berikutnya. Adat ini dapat berubah-ubah sesuai dengan situasi dan perkembangan zaman, sehingga dapat disamakan dengan peraturan pelaksanaan dari suatu ketentuan adat

d. Adat yang Teradat

Adat ini merupakan konsensus bersama yang dirasakan baik, sebagai pedoman dalam menentuhan sikap dan tindakan dalam menghadapi setiap peristiwa dan masalah-masalah yang dihadapi oleh masyarakat. Konsensus itu dijadikan pegangan bersama, sehingga merupakan kebiasaan turun-temurun. Oleh karena itu, "adat yang teradat" ini pun dapat berubah sesuai dengan nilai-nilai baru yang berkembang.

\section{METODE}

\section{Desain Penelitian}

Untuk mencapai tujuan dari penelitian ini akan dilakukan dengan cara mengikuti kerangka kerja sebagai berikut :

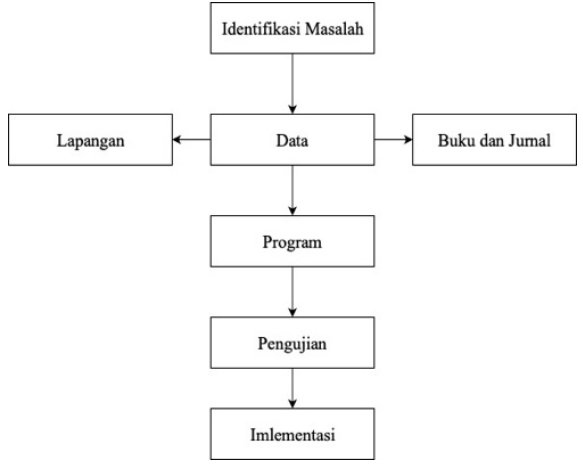

Gambar 1. Desain penelitian 


\section{Identifikasi Masalah}

Merupakan tahap awal dari penelitian ini. Masalah yang diidentifikasi adalah untuk mengetahui permasalahan yang yang terjadi di dalam kegiatan untuk mengetahui jenis masalah dan cara penangana yang kemudian diimplementasikan dalam sistem guna untuk menghasilkan kesimpulan untuk memecahkan suatu masalah.

\section{Pengumpulan Data}

Metode yang digunakan dalam penelitian ini yaitu :

a. Literatur Pengumpulan data dari literatur dilakukan dengan pembacaan literatur-literatur yang memuat pembuatan game. Adapun literatur yang digunakan dalam pengumpulan data ini yaitu berupa kumpulankumpulan jurnal dan buku buku adat melayu Riau. Hasil yang diperoleh dari pengumpulan data dari literatur ini yaitu jenis jenis adat melayu Riau.

b. Observasi Suatu metode pengumpulan data yang dilakukan dengan mengamati langsung, melihat dan mengambil suatu data yang dibutuhkan di tempat penelitian itu dilakukan

c. Wawancara merupakan salah satu teknik pengumpulan data yang dilakukan Melalui tatap muka langsung dengan narasumber dengan cara tanya jawab Langsung. Wawancara dilakukan dengan staf Dinas Kebudayaan Provinsi Riau, yang berhubungan dengan data yang terkait.

\section{Analisis Data}

Hasil yang didapat berdasarkan wawancara dari informan dan data sekunder yang didapat berdasarkan kutipan buku nantinya akan dijadikan landasan penulis untuk mendukung perancangan media agar hasil yang diperoleh menjadi satu arah yang sesuai dengan permasalahan yang dihadapi dalam penelitian ini. Sehingga didapatkan jawaban yang valid serta bisa di pertanggung jawabkan. Guna menambah ide maupun sebagai referensi dalam pembuatan game sangatlah penting dilakukan studi eksisting. Dalam hal ini pembuatan game adat melayu Riau ini studi eksisting dilakukan dengan mempelajari game-game yang sudah ada sebelumnya.

\section{Perancangan}

Perancangan dimulai membuat sketsa terlebih dahulu, untuk menetukan dan membuat dimana saja tata letak gambar dan permainan yang bagus nantinya. Supaya tidak membuat user bingung dalam memainkan aplikasi.

1. Sketsa tampilan menu utama

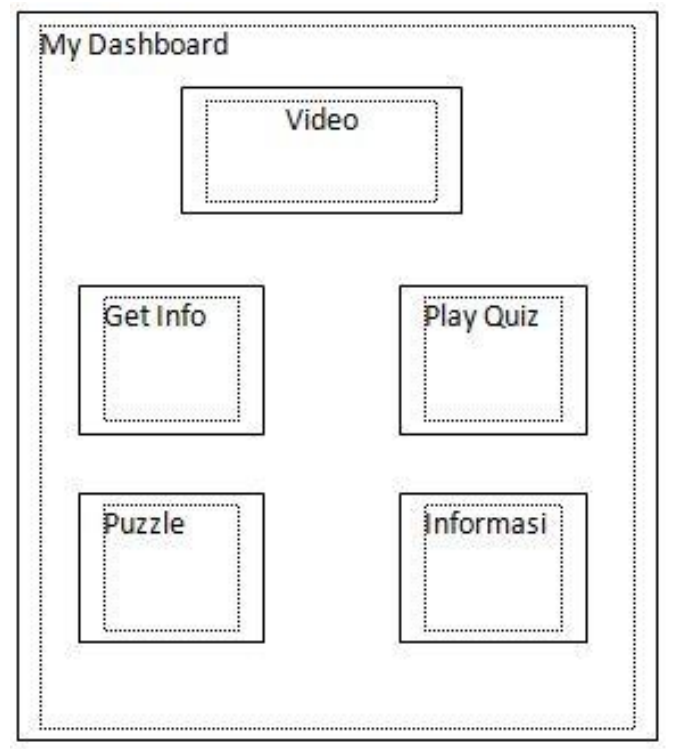

Gambar 2. Sketsa tampilan menu utama

Tampilan ini nantinya akan memperlihatkan tentang ikon yang bisa di akses oleh pengguna seperti video, get info, play quiz, puzzle, dan informasi. Dimana didalamnya terdapat informasi dan game. 
2. Sketsa tampilan Get Info

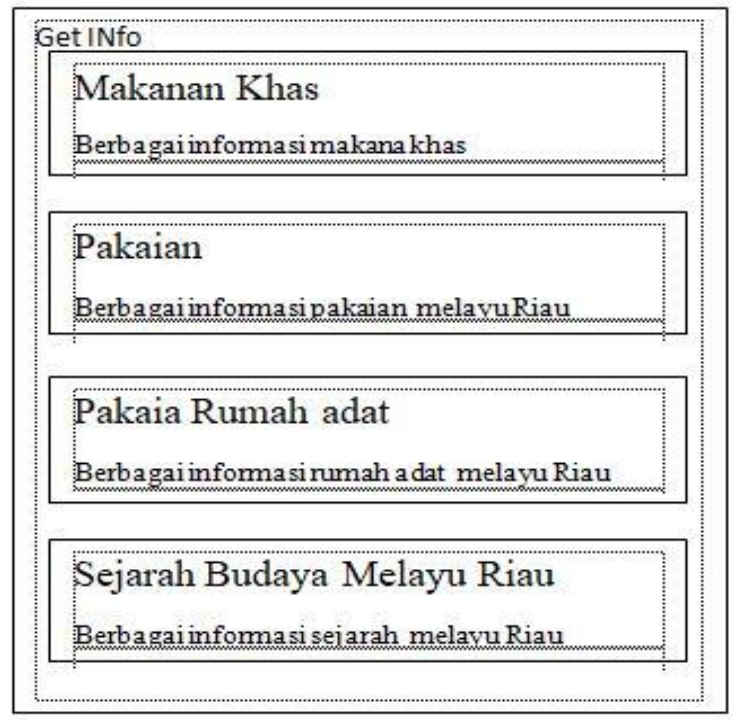

Gambar 3. Sketsa tampilan Get Info

Get Info ini menampilkan informasi tentang makanan khas pakaian rumah adat sejarah dan pariwisata yang bisa di akses oleh user nantinya.

3. Sketsa tampilan play quiz

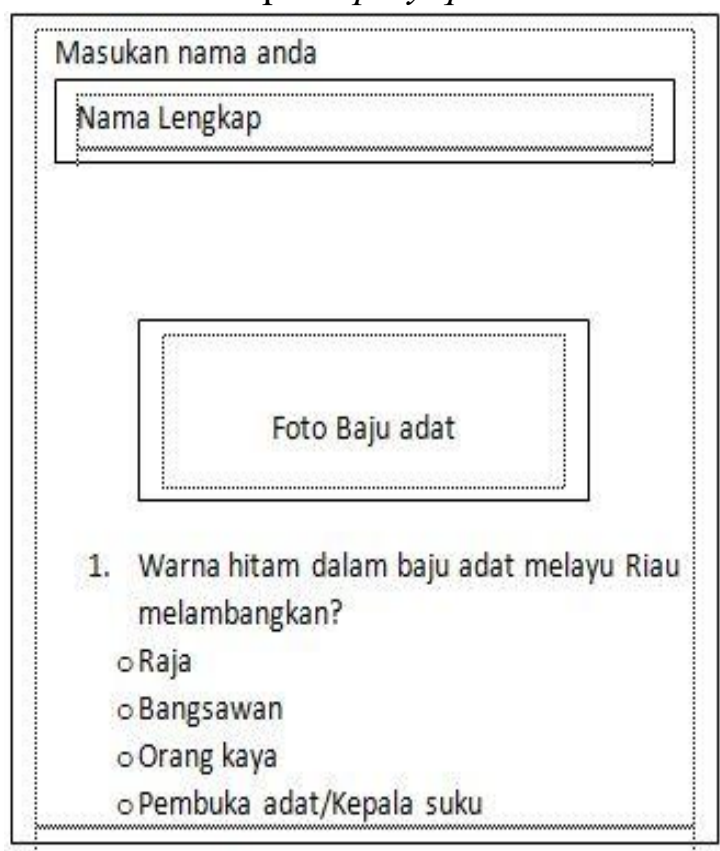

Gambar 4. Sketsa tampilan play quiz

Tampilan ini nantinya akan berisikan pertanyaan yang bisa di jawab oleh user. Disini pertanyaannya akan dibuat acak untuk memper sulit dan melihat pemahaman user dalam mengenal budaya melayu Riau.

4. Sketsa tampilan pilihan quiz

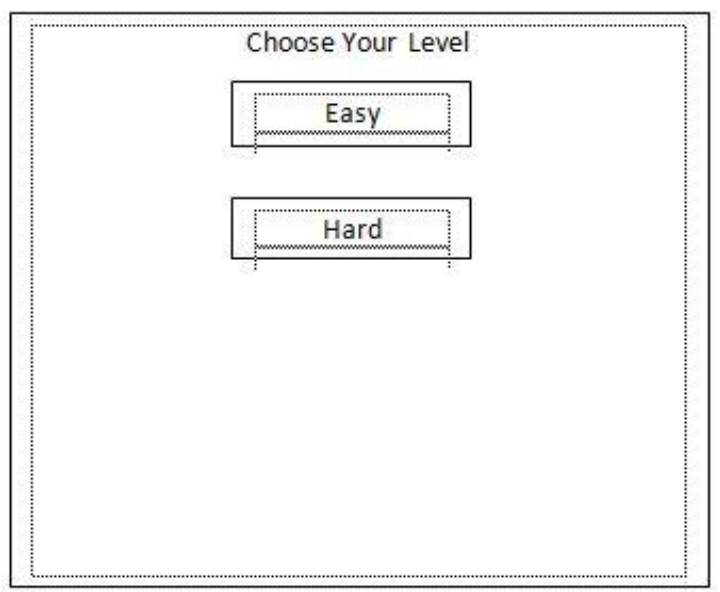

Gambar 5. Sketsa tampilan pilihan quis

Tampilan ini nantinya akan memerlihatkan pilihan puzzle yang bisa dipilih oleh user. Terdapat dua pilihan yaitu easy dan hard, keduanya memiliki tingkat kesulitan yang berbeda-beda nantinya untuk membuat pengguna tidak bosan. Kedua puzzle ini nantinya juga memeliki banyak kolom yang berbeda beda.

5. Sketsa tampilan quis easy

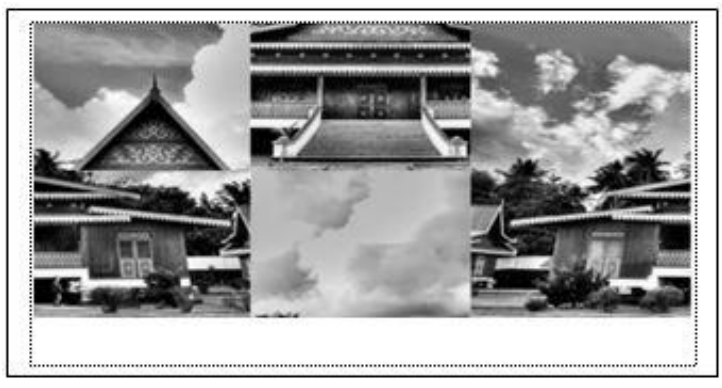

Gambar 6. Sketsa tampilan quis easy

Halaman ini nantinya akan memperlihatkan puzzle quis easy dimana nantinya puzzle ini dibuat sesederhana mungkin untuk memudahkan user untuk memainkannya. Nantinya disini akan dibuat dua kali sentuhan untuk memudahkan user menyelesaikan game ini sesuai dengan namanya game easy. 


\section{Sketsa tampilan quis hard}

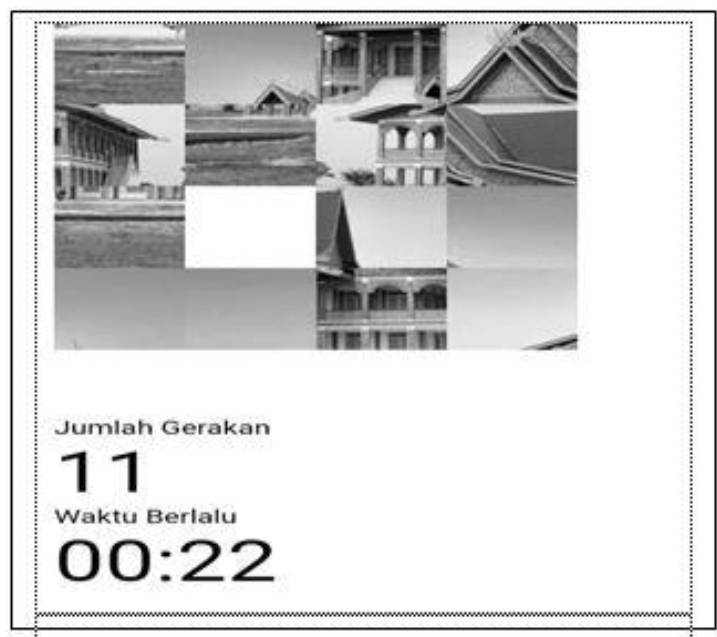

Gambar 7. Sketsa tampilan quis hard

Halaman ini nantinya akan dibuat puzzle yang cukup sulit. Puzzle ini hanya bisa dilakukan dalam satu kali sentuhan untuk mengerakannya, ini yang membedakan dengan yang easy tadi yang bisa dilakukan dua kali gerakan untuk memaikannya. Tingkat kesulitanyapun cukup tinggi dikarenakan puzzle ini memeiliki enam belas kolom yang harus disusun. Beda dengan puzzle easy yang hanya memiliki enam kolom saja.

7. Sketsa tampilan informasi

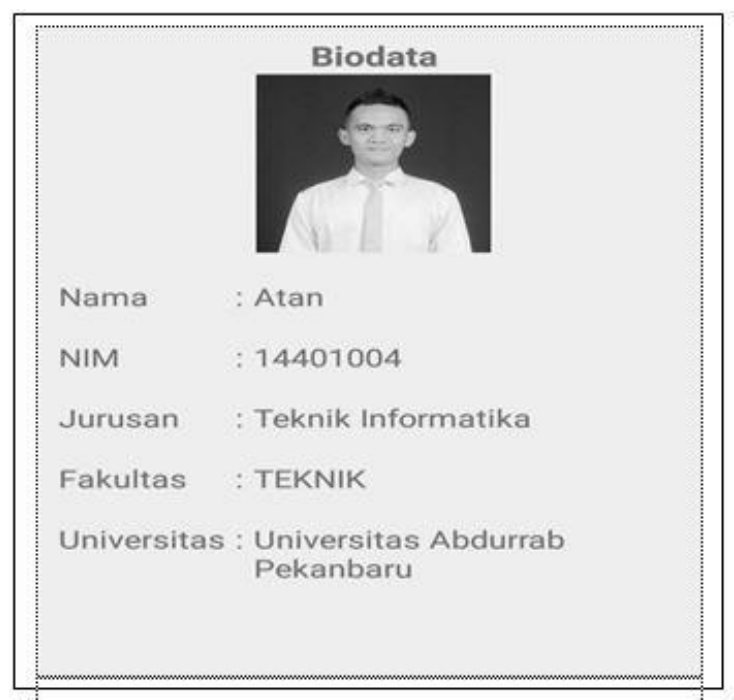

Gambar 8. Sketsa tampilan informasi

Halaman ini nantinya hanya berisi informasi tentang biodata tentang penulis

\section{Pengujian}

Pengujian aplikasi "adat melayu riau" yang telah dibuat dalam penelitian ini dilakukan dengan menggunakan menggunakan motode black-box. Pengujian ini berisi rangkaian fungsi-fungsi yang terdapat dalam aplikasi. Pengujian ini bertujuan untuk memerikasa fungsi-fungsi dalam aplikasi, apakah sesuai dengan yang diinginkan atau tidak. Pengujian ini jugan untuk melihat apakah masih ada kesalahan sehingga secepatnya dapat didicarikan solusi. Pengujian dilakukan dengan smartphone dengan sistem android

\section{Implementasi}

Tahap implementasi merupakan tahap translasi desain yang telah dirancang ke dalam kode program, implementasi yang dilakukan meliputi implementasi rancangan antarmuka (user interface). Implementasi Rancangan Antarmuka (user Interface) Sesuai dengan rancangan sketsa yang sudah dibuat, maka hasil implemantasi dari rancangan antarmuka kita dapat mulai merancang tampilan yang akan dibuat untuk aplikasi ini.

\section{HASIL}

\section{Pembuatan Aplikasi}

Dalam aplikasi ini kita menggunakan Android Studio dan untuk pengisian datanya kita menggunakan web. Disini admin dapat membagikan beberapa informasi dan juga pertanyaan agar dapat dilihat dan dijawab oleh user melalui aplikasi Android tersebut.

a. Tampilan Dashboard pada Admin

Pada tampilan ini terdapat kata pembuka yaitu tentang sejarah budaya melayu. Pada tampilan ini admin akan menjelaskan tentang budaya melayu baik 
itu dalam segi, makanan khas melayu, rumah adat melayu, pakaian adat, wisata, pertanyaan, nilai dan gambar.

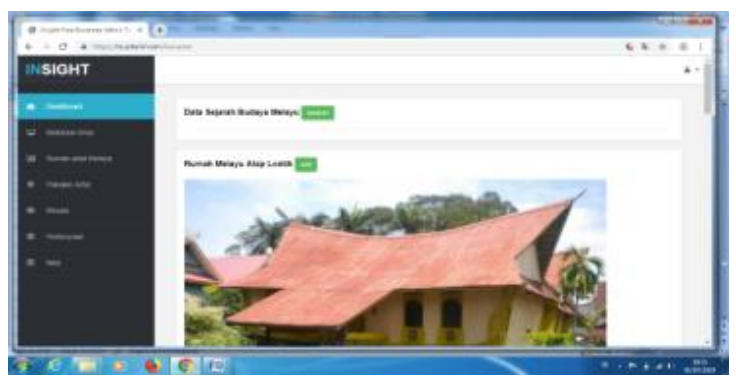

Gambar 9. Tampilan Dashboard pada admin

b. Pengisian Data Makanan Khas

Pada bagian ini admin memasukan data-data makanan khas melayu dan berikut dengan gambarnya. Agar user dapat mengetahui makanan khas melayu utnuk menjadi pengetahuan dan pembelajaran.

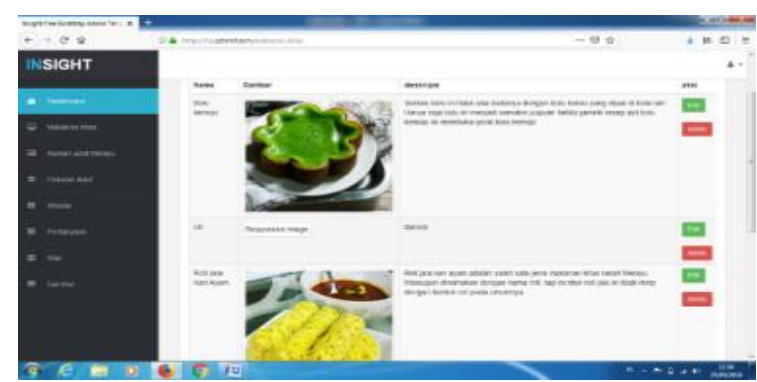

Gambar 10. Pengisian data makanan khas Melayu

c. Data Rumah Adat Melayu

Disini admin menjelaskan fungsi dan bentuk-bentuk rumah adat Melayu beserta contoh foto rumah tersebut agar banyak anak-anak yang memahami makna dari rumah adat melayu tersebut.

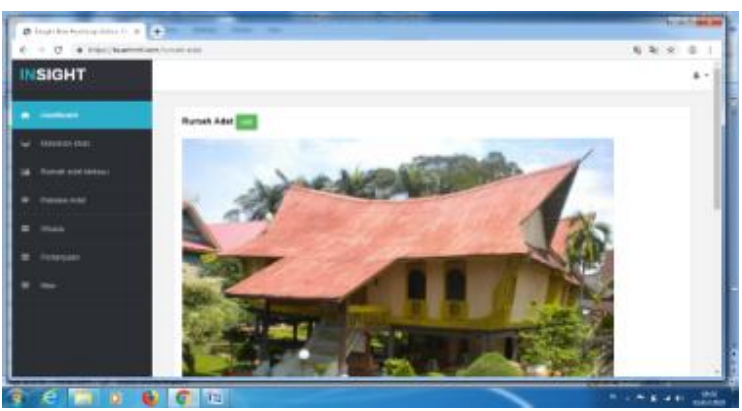

Gambar 11. Data Rumah Adat Melayu

\section{d. Pakaian Adat Melayu}

Disini admin memberikan informasi mengenai pakaian adat yang dapat di akses oleh user, dsini terdapat pakaian melayu laki-laki dan perempuan.

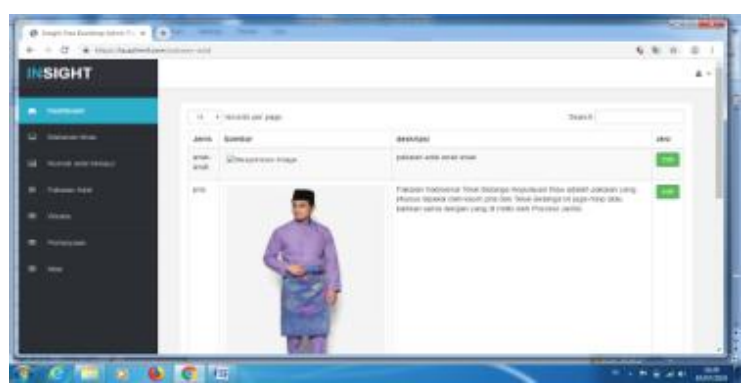

Gambar 12. Data Pakaian Adat Melayu

e. Pengisian soal Quiz.

Disini admin memberikan soal-soal mengenai adat melayu Riau. Dimana nantinya bisa dijawab oleh pengguna atau user.

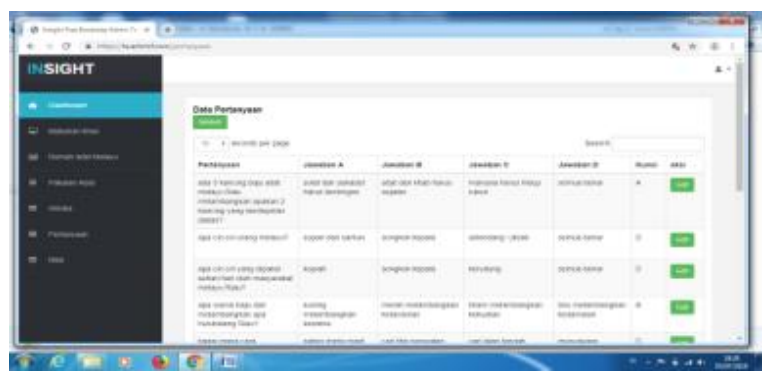

Gambar 13. Pengisian Soal Quiz

Setelah admin selesai mengisi data yang diperlukan untuk aplikasi edukasi puzzle maka user sudah dapat mengakses informasi dan melalui smartphone.

1. Tampilan Halaman Awal

Pada tampilan halaman awal aplikasi ini lansung menampilkan beberapa ikon seperti, Get Info, Play Quiz, Solve Puzzle, dan Informasi. Karena aplikasi ini diharapkan dapat memberikan interface yang menarik kepada user untuk mencari informasi, seperti gambar dibawah ini. 


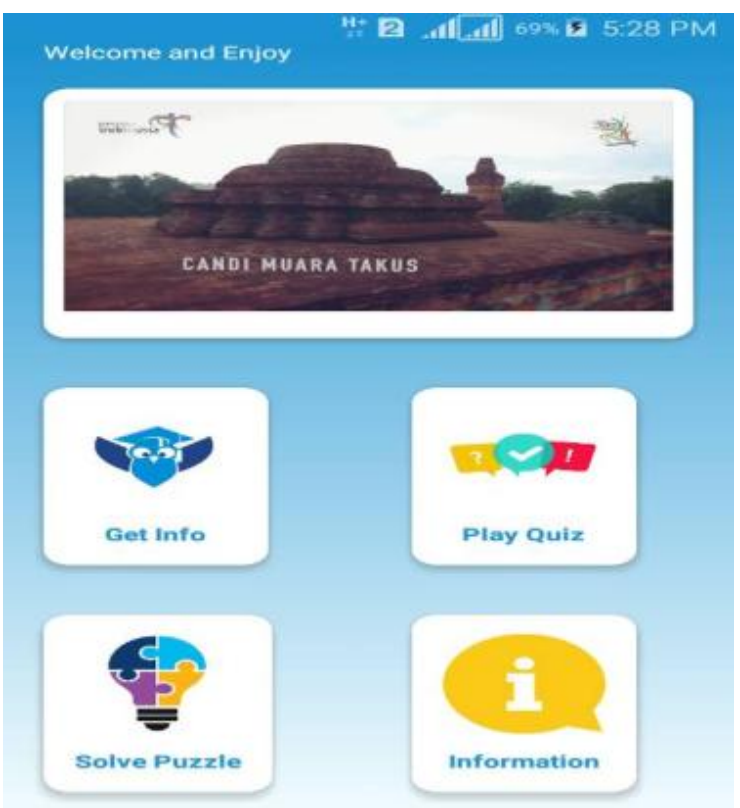

Gambar 14. Halaman Awal

Halaman ini memperlihatkan tentang tampilan halaman utama pada bentuk aplikasi ini. Ada empat kotak yang bisa di akses oleh user untuk membantu user dalam mencari informasi dan satu video tentang wisata Riau.

2. Tampilan Get Info

Pada halaman info disini dijelaskan tentang berbagai macam yang terdapat pada adat melayu, mulai dari makanan, pakaian, budaya wisata, sejarah dan lain sebagainya. Sebagai informasi awal yang dapat diakses oleh user

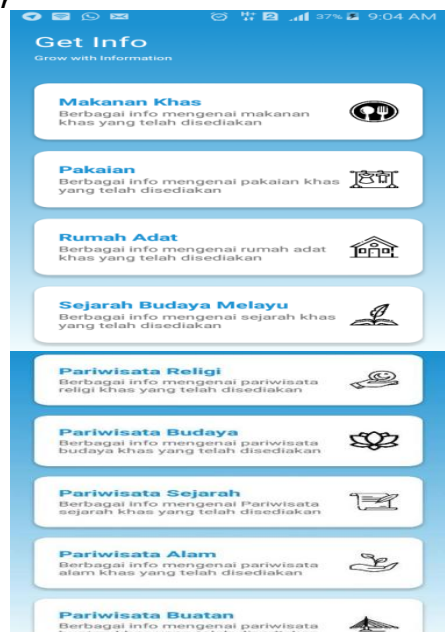

Gambar 15. Tampilan pada halaman Get Info
Halaman ini memperlihatkan jenis-jenis tentang pariwisata yang di miliki oleh Provinsi Riau. Dimana di dalamnya terdapat gambar-gambar yang memudahkan pengguna untuk mendapatkan informasi tentang adat budaya melayu Riau.

\section{Tampilan Halaman Play Quiz}

Tampilan yang terdapat pada play quiz ini adalah, beberapa pertanyaan yang dapat dijawab oleh user berdasarkan pada informasi yang didapat pada halaman sebelumnya itu get info itu sendiri.

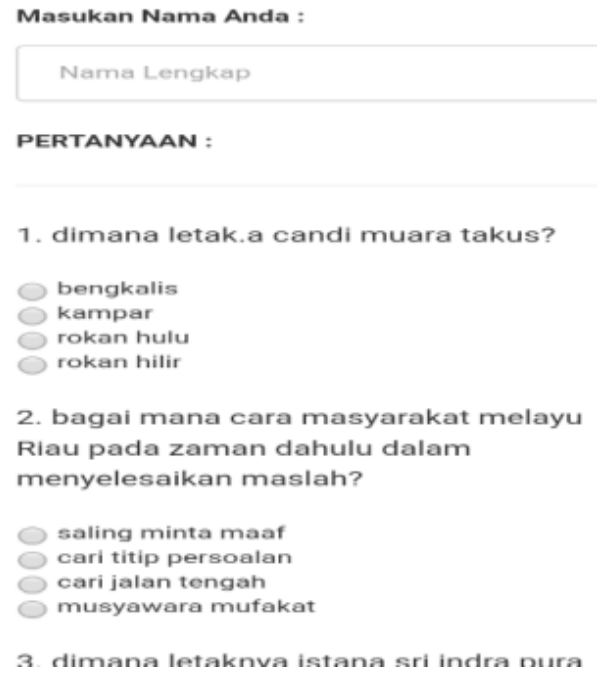

Gambar 16. Halaman Play Quiz

4. Tampilan Halaman result

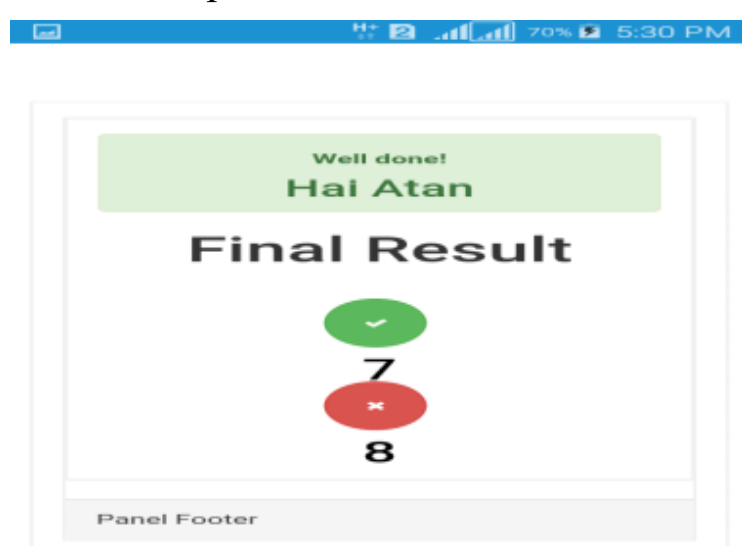

Gambar 17. Halaman Result 
Halaman ini adalah hasil dari berapakah benar dan berapakah salah pertanyaan yang di jawab oleh user.

\section{Tampilan Halaman Solve Puzzle}

Pada halaman solve puzzle ini terdapat dua pilihan model puzzle yang dapat kita pilih berdasarkan tingkat kesulitan yang kita inginkan. Disini ada pilihan Easy atau Hard. Seperti pada gambar berikut ini.

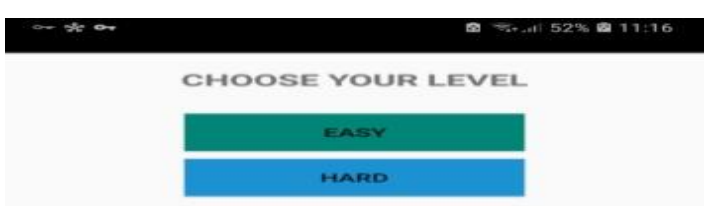

Halaman ini termasuk quiz yang cukup mudah dimainkan untuk pemula game. Karena di halaman ini pengguna bisa menekan dua kali untuk menggerakan puzzle tersebut, untuk memudahkan pengguna menyelesaikan quiz secara muda dan cepat.

7. Tampilan Halaman Hard

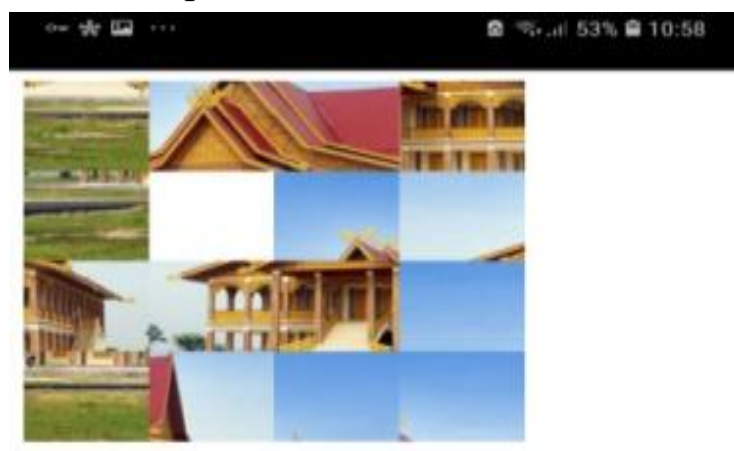

Jumlah Gerakan

28

Waktu Berlalu

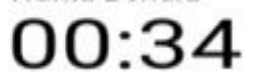

\section{๑ ए 口 $\leftarrow$}

Gambar 18. Halaman Solve Puzzle

Halaman ini memberikan pilihan kepada pengguna untuk memilih level mana yang akan di mainkan oleh pengguna. Terdapat dua tingkatan permainan yang dapat dimainkan oleh pengguna, yaitu easy dan hard. Dimana ada tingkatan atau kesulitan yang berbeda-beda dalam level tersebut.

\section{Tampilan Halaman Easy}

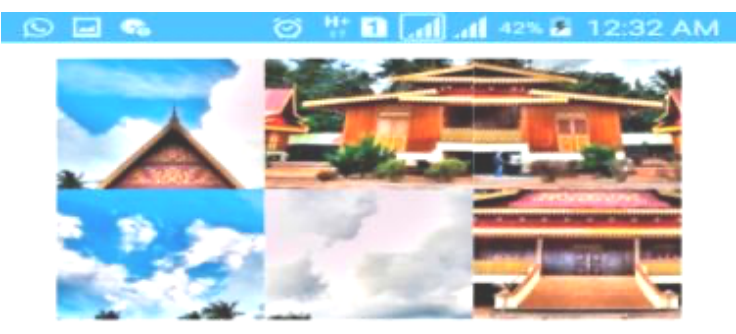

Gambar 19. Halaman Easy

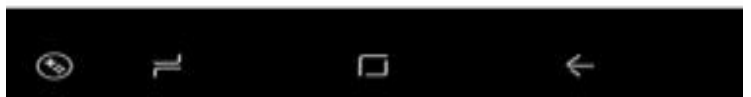

Gambar 20. Halaman Hard

Halaman ini adalah halaman quis hard. Quiz yang memiliki tingkat kesulitan yang cukup tinggi, dan sangat susah untuk diselesaikan. Karena disini terapat enam belas kolom puzzle. Setiap kolom atau kotak hanya dapat ditekan satu kali untuk mepersulit pengguna untuk menyelesaikan game ini. Disini pun terdapat hitungan jumlah gerakan yang user atau pengguna lakukan pada game ini. Tidak hanya itu disini pun kita dapat melihat seberapa lama waktu yang kita habiskan untuk menyelesaikan game ini. 


\section{Tampilan Halaman Informasi}

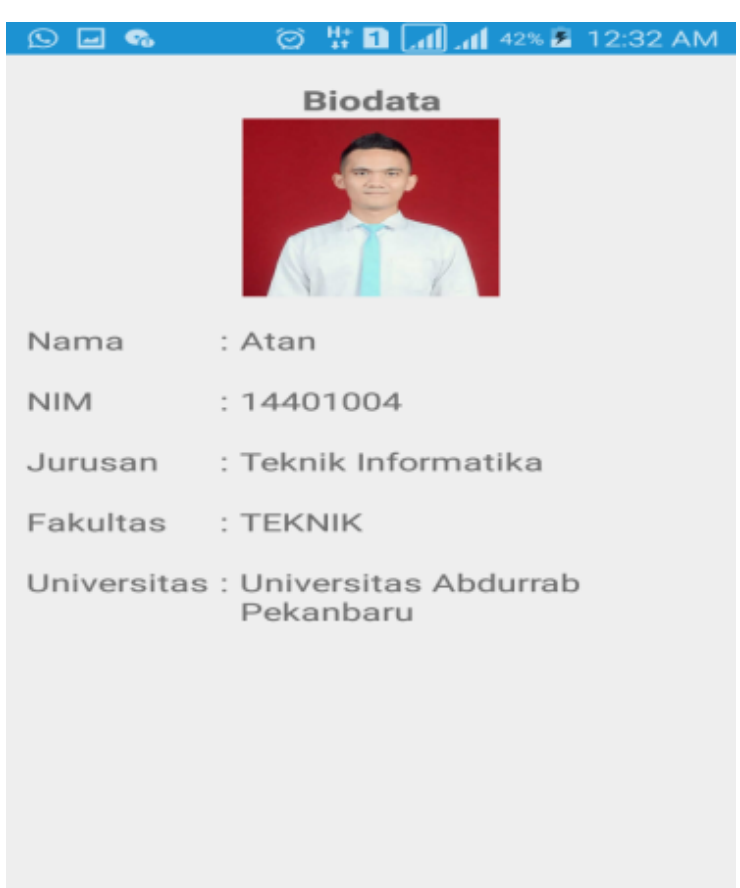

\section{Gambar 21. Halaman Informasi}

Pada halaman ini terdapat Informasi mengenai biodata admin. Halaman ini sangat sederhana, yang mana hanya menampilkan informasi biodata admin saja, berupa foto dan teks.

\section{KESIMPULAN}

Dari penjelasan dan pembahasan keseluruhan materi pada bab-bab sebelumnya, dalam rangka menyelesaikan penelitian ini, maka dapat diambil beberapa kesimpulan yaitu :

1. Dengan selesainya penelitin membuat aplikasi ini terdapat beberapa informasi yaitu pengenalan budaya melayu Riau, pariwisata rumah adat pakaian adat dan game.

2. Dengan adanya aplikasi pengenalan budaya melayu Riau berbasis android ini peneliti berharap dapat memberikan suatu pemikiran untuk lebih baik lagi serta menjadikan user friendly.
3. Dengan adanya aplikasi ini peneliti pun dapan belajar untuk lebih mengerti keinginan msyarakat dalam mencari informasi.

4. Diharapkan hasil dari penelitian ini dapat membantu user dalam pencarian informasi. 


\section{DAFTAR PUSTAKA}

[1] Agustina, Candra. (2015). Aplikasi Game Pendidikan Berbasis Android Untuk Memperkenalkan Pakaian Adat Indonesia. IJSE-Indonesian Journal on Software Engineering, 1(1).

[2] Barry,Fachrul. 2014, Perancangan Aplikasi Penjualan Batik Berbasis Android.

[3] Disa, Syaharullah. 2012. Simulasi sistem untuk memperkirakan penjualan sepatu per harinya dengan metode Monte Carlo

[4] Ekawati, Putri Ludvyah, dkk. (2015). Pemanfaatan Teknologi Game Untuk Pembelajaran Mengenal Ragam Budaya Indonesia Berbasis Android. Jurnal LINK, 22(1), 30-36.

[5] Fauzy, Muhammad, Rinda Cahyana, and Dewi Tresnawati. (2013). Pembuatan Game Edukasi Pengenalan Karies Untuk Anak Usia 6-8 Tahun. Jurnal Algoritma, 9(01).

[6] Imania, Khairani Larasati, Riama Maslan Sihombing, and Intan Rizky Mutiaz. (2014). Pemanfaatan Produk Budaya Modern dalam Bentuk Game untuk Mobile Gadget sebagai Media Pelestarian Budaya Tradisional (Dengan Studi Kasus Kue Tradisional Jawa Barat). Journal of Visual Art and Design, 6(1), 17-28.s

[7] Mahdiyah, Evfi, and Asprindo Fatayat. (2017). Aplikasi Multimedia Pengenalan Seni Budaya Provinsi Riau Menggunakan Adobe Flash. Riau Journal Of Computer Science, 3(1), 63-
70.

[8] Novandya, Adhika. (2012). Aplikasi Pengenalan Budaya dari 33provinsi di Indonesia Berbasis Android. Prosiding KOMMIT.

[9] Putra, Febriyanto Pratama. (2012). Pembuatan Game Animasi 3d Role Playing Game Untuk Pendidikan Budaya Dengan Unity3d Dan Bahasa Pemrograman C (Doctoral dissertation, Universitas Muhammadiyah Surakarta).

[10] Purwanto, Eko, and Margareta Evi Yuliana. (2016). Penerapan Animasi Pertunjukan Wayang Sebagai Media Pendidikan Budi Pekerti dan Memperkenalkan Budaya Bangsa Kepada Anak Usia Dini. Jurnal SainsteCh, 1(6).

[11] Salman, Afan Galih, Natalia Chandra, and Norman. (2013). Game Edukasi Pengenalan Kebudayaan Indonesia Berbasis Android. ComTech: Computer, Mathematics and Engineering Applications, 4(2), 11381154.

[12] Teng, Muhammad Bahar Akkase. (2017). Filsafat Kebudayaan dan Sastra (dalam Perspektif Sejarah). Jurnal ilmiah budaya, 5(1 Juni).

[13] Utomo, Pandu Rukmi, and Rahmatsyam Lakoro. (2012). Perancangan Concept Art Game Berlatar Budaya Majapahit sebagai Media Komunikasi Budaya. Jurnal Sains dan Seni ITS, 1(1), F1-F5.

[14] Widianti, Santi, Dede Anggriawan, and 
Iwan Setiadi.(2016).Aplikasi interaktif sebagai media pembelajaran budaya Indonesia. Syntex

Jurnal

Informatika, 3(02).

[15] Yanie, Dewi Andri, Soewarto Hardhienata, and Andi Chairunnas. (2014). Aplikasi pengenalan permainan tradisional dari jawa barat berbasis multimedia. Jurnal Online Mahasiswa (JOM) Bidang Ilmu Komputer/Informatika, 3(3). 